\title{
Da fisiologia à economia política: o itinerário intelectual de Quesnay em direção ao Tableau Économique
}

\author{
From physiology to political economy: Quesnay's intellectual \\ itinerary towards the Tableau Économique
}

FERNANDO RIBEIRO

NELSON MENDES CANTARINO*

\begin{abstract}
RESUMO: As interfaces entre a formação da teoria econômica e outros ramos do conhecimento raramente são exploradas na história do pensamento econômico. $\mathrm{O}$ artigo busca trazer uma contribuição original na análise dos debates que ocorreram na medicina e na filosofia natural no contexto em que o pensamento fisiológico e natural de Quesnay (1684-1774) foi desenvolvido. Argumenta-se que as abordagens fisiológicas de Quesnay podem estar relacionadas com o Tableau Economique (1758-1766) em um sentido muito diferente do que o oferecido por Foley (1973) e pela maioria dos livros de história do pensamento econômico pelo qual o Tableau deve ser visto como um analogia do sistema circulatório.

PALAVRAS-CHAVE: François Quesnay; Tableau Économique; economia política; História do Pensamento Médico.
\end{abstract}

ABSTRACT: The interfaces between the formation of economic theory and other branches of knowledge are rarely explored in the history of economic thought. The article seeks to bring an original contribution in analyzing the debates that took place in natural philosophy and medicine in the context in which the physiological and natural thought of Quesnay (1684-1774) was developed. It is argued that the physiological approaches of Quesnay may be related to the Tableau Economique (1758-1766) in a very different sense from that offered by Foley (1973) and by most textbooks History of Economic Thought whereby the Tableau should be seen as an analogy of the circulatory system.

KEYWORDS: François Quesnay; Tableau Économique; political economy; History of Medical Thought.

JEL Classification: A12; B11; B31.

\footnotetext{
* Professor-Doutor. Departamento de Economia da Pontificia Universidade Católica-PUC-SP e Instituto de Ensino e Pesquisa - INSPER, E-mail: fernandoribe@hotmail.com; Professor-Doutor. Instituto de Ensino e Pesquisa - INSPER e Fundação Escola de Comércio Álvares Penteado - FECAP. E-mail: nmcantarino@hotmail.com. Submetido: 3/Fevereiro/2015: Aprovado: 18/maio/2015.
} 


\section{INTRODUÇÃO}

Pode-se argumentar que o sistema fisiocrático foi construído, pelo menos parcialmente, para fornecer uma base teórica para a necessária reforma tributária quando a Coroa francesa estava à beira da falência, após a Guerra dos Sete Anos (1756-1763). O Tableau Économique, publicado em uma série de versões entre fins de 1758 e 1766, tem dois objetivos: representar os fluxos agregados de receitas e despesas num quadro único e, mais importante, fornecer as ferramentas analíticas necessárias para julgar a melhor política fiscal a ser adotada pelo Parlamento e pela Coroa francesa (Bauer, 1890; Meek, 1960; Vardi, 2012; Orain, 2013)ํ․

"Tentei construir um Tableau fundamental da ordem econômica com a finalidade de mostrar as despesas e os produtos de uma forma que é fácil de entender, e com a finalidade de formar uma opinião clara sobre a organização e desorganização que o governo pode trazer (Quesnay, 1758, citado em Kurz, 1984, p. 112)."

O contexto do Iluminismo, onde a economia é considerada como um organismo vivo, juntamente com a formação prévia de Quesnay (1684-1774) em cirurgia e medicina, deu à luz o entendimento de que o Tableau Économique poderia ser abordado como uma analogia do sistema circulatório, descoberto e descrito por Harvey (1578-1657), em meados do século XVII (Foley, 1973; Christensen, 1994).

Este trabalho pretende abordar uma disputa de longo prazo entre estudiosos de Quesnay. Para colocar nas palavras de Foley (1973, p. 121.): “Poderia Quesnay ter obtido suas noções de circulação de bens e de dinheiro na sociedade a partir de seu conhecimento prévio das descobertas de Harvey sobre a circulação do sangue?”. Ao fazer isso, o artigo aplica aquilo que Marcuzzo (2008, p. 111) descreve como “análise contextual”.

$\mathrm{O}$ artigo, em primeiro lugar, descreve a analisa a influência e a trajetória intelectual do Tableau Économique na História do Pensamento Econômico visando a

\footnotetext{
${ }^{1}$ As duas primeiras versões do Tableau circularam de forma restrita e foram publicadas no final de 1758 e início de 1759. É provável que apenas Mirabeau (1715-1789), além de Quesnay, tivesse familiaridade com essas primeiras versões, as quais se caracterizam, também, por serem lacônicas, em linha com as bases epistemológicas da fisiocracia e de Quesnay (1756). Em 1761, uma versão do Tableau foi publicada na segunda parte do sexto volume da obra seriada de Mirabeau, L'ammi des Hommes. Em 1763, a Philosophie Rurale, escrita por Quesnay e Mirabeau, traz mais uma versão do Tableau. Por fim, em junho de 1766 uma última versão foi publicada no Journal de l'Agriculture, du Commerce et des Finances. Em 1767, Dupont de Nemours (1739-1817) publicou mais uma versão do Tableau na compilação Phisiocratie. Para detalhes da história da publicação do Tableau ver Meek (1960) e Van den Berg (2002). Para as relações entre epistemologia e as primeiras versões do Tableau consultar Vardi (2012).

2 "By context I mean the set of questions and answers which framed theories and concepts, the intellectual interlocutors to whom they were addressed and 'the state of the art' at the time of their conception. The framework consists of facts regarding time, place and circumstances, about which knowledge and information have first to be dug out and then used to make sense of what is being interpreted or, as far as possible, illuminated." (Marcuzzo, 2008, p. 111). Em seu artigo, Marcuzzo apresenta e discute outros métodos de historiografia do pensamento econômico: Exegese textual; Recriação Racional; Análise contextual e Narrativa Histórica.
} 
uma definição precisa da questão em pauta. As interfaces entre a formação da teoria econômica e demais ramos do conhecimento, tais como matemática, engenharia e medicina, são raramente exploradas na historiografia do pensamento econômico. $\mathrm{O}$ artigo busca trazer uma contribuição original nesse ponto, na medida em que analisa os debates que se desenrolaram na filosofia natural entre fins do século XVII e meados do século XVIII. Trata-se de se precisar o contexto no qual o pensamento fisiológico e natural de Quesnay se desenvolveu. Esse esforço está subordinado ao objetivo de se identificar com máxima precisão o posicionamento relativo de Quesnay como médico e filósofo natural dentre as várias teorias em disputa no período.

Ainda nesse ponto é feito um relato detalhado do pensamento fisiológico de Quesnay. Argumenta-se que as doutrinas fisiológicas de Quesnay podem ser relacionadas ao Tableau em um sentido bastante diferente daquele oferecido por Foley (1973) e pela maioria dos livros didáticos de História do Pensamento Econômico. Para reforçar este ponto, o próximo tópico é dedicado à construção de críticas à interpretação de Foley (1973), segundo a qual o Tableau deveria ser visto como uma analogia do sistema circulatório. As considerações finais concluem o artigo.

\section{O TABLEAU ÉCONOMIQUE: ENTRE A “ECONOMIA ANIMAL” E A ECONOMIA POLÍTICA}

Muita tinta foi derramada tentando explicar o interesse de Quesnay em economia política por volta de 1750. Como Steiner (2003) e Théré (1998) mostram, assuntos econômicos faziam parte do debate público na França ao longo do século XVIII. Théré (1998) contou 1.946 autores de publicações econômicas (panfletos, brochuras, livros e assim por diante) entre 1550 e a Revolução Francesa. Desse total, havia 127 médicos e cirurgiões $(6,5 \%)$. No entanto, no momento em que Quesnay começa a publicar em Economia Política, médicos e cirurgiões são responsáveis por 7,8\% do total de autores (Théré, 1998, pp. 36-37) .

De acordo com Adam Smith (1723-1790), Quesnay era um "médico muito teórico". No capítulo IX do Livro IV da Riqueza das Nações, Smith fornece uma resenha da doutrina fisiocrática, bem como o primeiro registro de uma possível herança de formação médica ao raciocínio econômico de Quesnay. Em uma digressão relacionada com os efeitos de diferentes sistemas de economia política sobre o progresso de uma nação, Smith ressalta que:

O Sr. Quesnay, ele próprio médico, e médico muito teórico, parece ter tido uma ideia do mesmo tipo, no tocante ao organismo político, e

\footnotetext{
${ }^{3}$ Uma razão para a vigência dos debates econômicos do período pode ser encontrada na série de quebras de safras na virada do século XVII ao século XVIII. Além disso, guerras recorrentes contra a Holanda, o Império Austríaco e a Inglaterra geraram fome, elevada mortalidade e crise fiscal (Orain, 2013; Steiner, 2003).
} 
parece ter imaginado que ele se fortaleceria e se desenvolveria somente sob um determinado regime preciso, o exato regime da liberdade e da justiça perfeitas (Smith 1983 [1776], p. 159).

Como é bem conhecido, Smith critica a hipótese da produtividade exclusiva da agricultura. Contudo, mesmo que a natureza do valor de troca e a origem do produto líquido tenham sido um tema em disputa entre Smith e Quesnay (para não mencionar Condillac (1715-1780), Ferdinando Galiani (1728-1787), Jean Baptiste Say (1767-1832)), Smith planejava dedicar a Riqueza das Nações à Quesnay. Apesar das críticas levantadas por Smith, o Tableau Économique teria uma influência duradoura na Economia Política ${ }^{4}$.

O Tableau ofereceu à Marx (1818-1883) o modelo para os sistemas dinâmicos de reprodução do capital descritos no Livro II de O Capital (1867). O mais simples dos modelos de Marx lida com uma economia que reproduz o mesmo nível de produção ao longo do tempo (Reprodução Simples). Marx reconhece a influência Tableau de Quesnay em uma carta a Engels escrita em julho de 1863 (Marx, 1966, p. 469; Gherke e Kurz, 1995) .

Walras (1834-1910), embora teça críticas sobre a teoria dos preços elaborada pelos fisiocratas, também reconhece as contribuições de natureza normativa derivadas de Quesnay e da Fisiocracia. Na Seção VII, Lição de $37^{\circ}$ de Elementos de Economia Política Pura pode-se ler:

Seríamos assim conduzidos a censurar-lhes muitas imperfeições, o que não impede, entretanto, que tenham sido não apenas a primeira, mas também a única escola de economistas que na França teve uma Economia Política Pura original e que, também, no meio de seus erros apareces-

\footnotetext{
${ }^{4}$ Essa influência, porém, ganharia ímpeto em meados do século XIX, quando Eugéne Daire (1843, 1844 e 1846) publicou um conjunto de textos de economistas franceses do século XVIII entre eles Turgot e os fisiocratas (Vardi, 2012). Para os contemporâneos, no entanto, a recepção do Tableau Économique, provavelmente a versão publicada em 1761 no sexto volume de L'Ami des Hommes de Mirabeau, pode ser considerada de duas maneiras: primeiro um ceticismo geral para a abordagem metodológica dos économistes a qual repousava em demasia em deduções derivadas de princípios gerais (Van den Berg, 2002; Vardi, 2002). Em segundo lugar, críticas mais técnicas e precisas foram feitas por Forbonnais (1767) e Graslin (1767). Para a descrição detalhada de tais críticas ver Van den Berg (2002).

${ }^{5}$ Marx (1863) desenvolve sua análise da Fisiocracia e do Tableau de Quesnay em Teorias da Mais-Valia. Marx elogia Quesnay e os Fisiocratas por terem identificado a fonte do excedente na produção direta, em vez de nas trocas. Contudo, segundo Marx, os fisiocratas apresentam o modo de produção capitalista ainda parametrizado por circunstâncias feudais. Em termos teóricos, Marx aponta que a contradição mais importante na estrutura teórica fisiocrática é identificar a mais-valia gerada na agricultura como a origem do excedente, contudo, um excedente medido em valores de uso gerado por meio de forças da natureza: "Daí as contradições neste sistema: ele foi o primeiro a explicar a mais-valia pela apropriação do trabalho alheio, e de fato a explicar esta apropriação em função da troca de mercadorias. Mas não vê que esse valor em geral é uma forma de trabalho social e que a mais-valia é trabalho excedente. Pelo contrário, ele concebe o valor meramente como valor de uso, a substância apenas como material, e mais-valia como uma mera dádiva da natureza [...]" (Marx, 1863, p. 70)
} 
sem opiniões de uma profundidade e de uma justeza extraordinárias, das quais duas subsistirão: uma, como base da Economia Social, a de que o Estado deve viver sobre o preço da renda fundiária, e a outra, como base da Economia Política Aplicada, a de que a livre concorrência é, salvo exceções bem motivadas, a regra geral e superior da produção da riqueza (Walras, 1996 [1874], p. 289).

No final do século XIX, a fisiocracia e Quesnay parecem ter caído no esquecimento (Bauer, 1890). Em meados do século XX a disputa relacionada à possível influência da formação médica de Quesnay nos seus subsequentes escritos econômicos foi levantada. Schumpeter (1954) e Meek (1960, 2003 [1962]) argumentam em favor da dissociação no raciocínio econômico de Quesnay de qualquer filosofia médica, fisiológica ou natural, adquirida durante a maior parte de sua vida profissional.

Sutter (1958) é a primeira tentativa de reconhecer as influências médicas e fisiológicas sobre os escritos econômicos de Quesnay. Foley (1973), por sua vez, foi capaz de moldar os debates vindouros no assunto graças a sua abordagem sobre a relação entre a circulação sanguínea e circulação de riquezas no Tableau Économique. Sua contribuição será discutida e desconstruída adiante neste trabalho.

Christensen (1994) oferece uma descrição detalhada das várias teorias em disputa na filosofia natural a respeito da natureza da matéria, seu movimento, sua geração, nutrição, química e metafísica, no período que vai de Descartes (1596-1650) até Quesnay. Ao fazê-lo, o autor fornece um resumo das possíveis influências sofridas por Quesnay na elaboração de suas teorias fisiológicas descritas em Quesnay (1747). No entanto, os caminhos teóricos que poderiam unir o pensamento social e natural no sistema de Quesnay são apresentados de forma breve e superficial. A fisiologia do Tableau, por exemplo, é uma reprodução dos argumentos levantados por Foley (1973).

Teoria do conhecimento, conforme apresentado em Quesnay (1736, 1747 e 1756) é o principal canal pelo qual Quesnay pode ter-se deslocado da teoria natural para o pensamento social de acordo com Groenewegen (2001). A evidência levantada pelo autor baseia-se na análise de textos de Quesnay à luz dos debates filosóficos mais amplos do período relacionados com a natureza da matéria (suas diferentes manifestações, o seu movimento e assim por diante). Porém, quando se trata de abordar as relações entre medicina e economia nas obras econômicas de Quesnay, o autor não oferece qualquer avanço na compreensão atual sobre a eventual autonomia ou não do pensamento econômico de Quesnay em relação à sua prévia formação em ciências naturais.

Mais recentemente, a hipótese de uma espécie de herança genética que uniria fisiologia e economia em Quesnay foi aparentemente abandonada. Charles (2003) argumentou que é preciso entender o Tableau como um dispositivo heurístico e retórico usado para clarificar e simplificar o modelo de Quesnay. Nesse sentido, o Tableau seria uma "Recreação Racional", inspirado no relógio do inventor francês Gaspard Grollier de Servière (1676-1745). As recreações racionais eram artefatos 
projetados para oferecer experiências mágicas, sensoriais e pedagógicas ao público nos séculos XVII e XVIII.

Interpretações puramente econômicas do Tableau provaram ser uma agenda de pesquisa mais frutífera. $\mathrm{Na}$ verdade, toda uma literatura surgiu desde a reinterpretação do Tableau feita por Meek (1960, 2003 [1962]). Esta literatura caracteriza-se por traduzir as ideias do passado para a economia contemporânea por meio da linguagem matemática (Maital, 1972; Barna, 1975; Eltis, 1975; Viaggi, 1985; Bilginsoy, 1994; Serrano e Mazat, 2013).

\section{QUESNAY COMO FISIOLOGISTA E SUA POSIÇÃO TEÓRICA NO PENSAMENTO MÉDICO NO SÉCULO XVIII}

Eu tenho a dizer que eu te abandono à sua má constituição, à inclemência do vosso ventre, à corrupção do teu sangue, à acrimônia da tua bile, e à feculência dos seus humores (Moliére, 1815 p. 197) ${ }^{6}$.

O pensamento científico do século XVIII ainda está sob a influência da metafísica. Uma das formas de manifestação deste traço distintivo é a influência duradoura da teoria dos humores e dos temperamentos na medicina. Uma herança direta de Hipócrates (460 a.C.-370 a.C.) e de Galeno de Pérgamo (129 a.C.-200 a.C.). Os humores são traduções dos elementos fundamentais da natureza na fisiologia do corpo. O Fogo está relacionado com a bílis amarela. O Ar é associado ao sangue. A Água é traduzida em fleuma e, finalmente, a terra é a bile negra. Cada um desses humores é responsável por um dado temperamento: bílis amarela, por exemplo, está relacionada com uma alma colérica. Indivíduos melancólicos sofrem por terem um excesso relativo de bile negra.

Para a medicina do século XVIII, a saúde é concedida por uma espécie de desequilíbrio pessoal nas dotações e nos fluxos de humores de cada indivíduo. Tais humores estão em constante movimento e o que causa esse movimento é uma questão central para a filosofia natural do século XVIII. A doença, portanto, é a manifestação de um grande desequilíbrio no fluxo e no estoque dos humores no corpo. A natureza busca restaurar os padrões originais dos estoques e dos fluxos dos humores. Dessa forma, o corpo tenta expelir o humor excedente. Cabe aos médicos ajudar a natureza em seu trabalho ministrando vomitivos, purgantes e, certamente, a sangria (Mitchell, 1979).

A descoberta de William Harvey (1578-1657), publicada em Frankfurt em 1628, estava longe de ameaçar este sistema. Os médicos, como profissionais do

\footnotetext{
${ }^{6}$ J'ai a vous dire que je vous abandonne à votre mauvaise constituition, à la intempérie de vos entrailles, à la corruption de votre sang, à l'àcreté de votre bile, et à la féculence de vos humeurs (Moliére, 1815 p. 197)
} 
direito ou estudiosos de teologia no século XVIII, foram treinados com base em uma herança da Antiguidade. Isso significa que qualquer avanço na ciência deveria ser muito mais uma elaboração dentro do conhecimento canônico do que uma transformação radical (Hamilton, 1951; Broman, 1989). Isso explica, pelo menos em parte, por que as descobertas de Harvey (1993 [1628]), Borelli (2001 [1680 e 1681]) e Malpighi (1958 [1661]) se articularam a um contexto onde os paradigmas de Hipócrates e Galeno permaneceram intactos. Friedman e Friedland (2000) ressaltam o quanto o caminho para a descoberta de Harvey foi constantemente bloqueado pelas dificuldades em se ajustar as descobertas anatômicas e fisiológicas de Vesalius (1514-1564) e de seus seguidores, como Bartolomeu Eustachio (15201574) e Gabriel Falopio (1525-1562), à tradição de Hipócrates e Galeno.

A circulação sistiêmica do sangue descrita por Harvey (1993 [1628]) articula-se à teoria do humor na medida em que o sangue faz os humores circularem pelos tecidos do corpo. É nesse ponto que Descartes (1596-1650), com a hipótese do movimento cíclico na dinâmica da natureza, se articula com o sistema circulatório descoberto por Harvey. Descartes (1677) argumentou que o corpo humano é uma máquina controlada por uma alma racional, localizada na glândula pineal. Este sistema mecânico opera sob as leis da hidrodinâmica, claramente descritas por Harvey na circulação sanguínea. O corpo humano é um sistema hidráulico que opera de acordo com as leis que estruturam a formam o movimento do universo, o qual é tido também como um sistema mecânico. Harvey (1628) se encaixa perfeitamente na teoria mecanicista de Descartes (1677).

Esta abordagem, compartilhada por Descartes, Newton (1643-1727) e Boyle (1627-1691), encontra-se sobre uma ontologia metafísica da ação no sentido de que a matéria é inteiramente passiva. Ela não consegue nem pensar e nem mover-se por sua própria vontade. Todo movimento na natureza foi dado por Deus no momento da Criação. Aqui, a analogia com a imagem do relógio, uma máquina mecânica cujo movimento, que em certo sentido se perpetua, e depende de uma força exógena, é bastante clara. Todo o movimento da matéria e da natureza, criado no alvorecer da vida, perpetua-se em todos os seres vivos por meio de inércia. Este é o elemento central da escola mecanicista.

Entre meados do século XVII e fins do século XVIII o debate central na filosofia natural estava estruturado em torno das causas e das leis que regem o movimento na matéria. A Iatrofísica (física do movimento) ou Iatrofisiologia (fisiologia do movimento) ou ainda Iatroquímica (química do movimento) representam a agenda de pesquisa do período, uma agenda que inclui a metafísica e a ciência experimental. A questão mais fundamental em disputa era o que faz e quais as leis que regem o movimento, particularmente nos tecidos e fluídos corporais (Mitchell, 1979, Christensen, 1994, Maquet, 1992). "Somos totalmente ignorantes sobre a origem e propagação do movimento nos corpos”, afirma Boerhaave (1668-1738) ${ }^{7}$ (apud Christensen, 1994, p. 252).

\footnotetext{
${ }^{7}$ Herman Boerhaave (1668-1738), médico e fisiologista holandês. Embora alinhado à escola mecanicista,
} 
Em meados do século XVIII, no entanto, a agenda mecanicista estava sob ataque de outras correntes do pensamento natural. Experimentos e observações biológicas e químicas demonstraram a sensibilidade autônoma em tecidos vivos. O movimento na matéria não aparecia mais como autônomo ou exógeno. Além disso, a hipótese de pré-formação, ou seja, a explicação dada por mecanicistas sobre a geração dos seres vivos segundo a qual novos organismos são simples alargamento dos germes presentes em gerações anteriores, estava em desacordo com a existência de híbridos, monstros e, mais importante, com a regeneração espontânea de tecidos descoberta no Pólipo de Trembley em 1740 (Christensen, 1994) . $^{8}$

Enquanto a escola mecanicista enfrenta uma crise intelectual, uma espécie de síntese ocorre na filosofia natural. Neo mecanicistas, materialistas e vitalistas formam um conjunto de hipóteses para explicar o movimento na matéria. Nesse contexto, uma das explicações para o movimento na natureza foi a hipótese do Princípio Vital. Embora a abordagem do Princípio Vital fosse de alguma forma hegemônica na medicina de meados do século XVIII, ela não fornecia qualquer unicidade em termos dos métodos terapêuticos entre os médicos. Por meio de uma amostra de práticas médicas daquele período, Mitchell (1979) oferece imagem do ecletismo em voga dentre os médicos com seus diferentes métodos terapêuticos e visões cosmológicas, mesmo no âmbito do paradigma do Princípio Vital. Quesnay operará no interior desse paradigma, e assim como seus demais colegas, também nutrirá um elástico ecletismo em suas doutrinas fisiológicas.

Essa é a maneira pela qual o Princípio Vital, misturado com os paradigmas de Hipócrates e de Galeno, dá sentido à prática médica, em meados do século XVIII. A filosofia natural de Quesnay, conforme descrito na segunda edição do Essai Physique sur L'Oeconomie Animale, de 1747, encaixa-se perfeitamente na abordagem vitalista, bem como na antiga teoria dos humores.

[...] Assim que a circulação sanguínea foi conhecida, o corpo humano foi entendido como uma máquina hidráulica. Foi considerado no tratamento de doenças o movimento dos humores nos vasos; todas as intenções dos médicos se limitaram a manter o equilíbrio entre sólidos e líquidos [...] (Quesnay, 1747, pp. 418-419)

\footnotetext{
não deixou de nutrir um ecletismo em termos de doutrinas fisiológicas acerca da natureza do movimento na matéria orgânica. Influenciou os escritos médicos de Quesnay por meio da hipótese de que o fogo seria o elemento atomístico e geral dos processos químicos e fisiológicos.

${ }^{8}$ As experiências de John Abraham Trembley (1710-1784) com pólipos de água doce demostrou a capacidade regenerativa dos tecidos orgânicos. "De alguma maneira, se entendia que a forma como se regenerava o pólipo certificava que a matéria era una entidade dinâmica e não apenas somente passiva.” Bernat (2013, p. 36).

${ }^{9}[$ [...] aussitôt que la circulation du sang a été connue, on n'a plus regardé le Corps Humain, que comme une machine hydraulique, on n'a envisagé dans la cure des maladies, que le movement des humeurs qui roulent dans les vaisseaux; toutes les intentions des médicens se sont bornées à entretenir l'equilibre, entre les solides et les liquides [...] (Quesnay, 1747, p. 418-419).
} 
Para Quesnay, contudo, o Princípio Vital devia ser encontrado na química. A influência de Boerhaave sob Quesnay passa pela proposição de que o fogo é um instrumento universal, presente, portanto, em todos os processos químicos. $\mathrm{O}$ fogo explica o calor da combustão, a fluidez e o movimento da matéria orgânica, bem como a luz.

Na mesma linha Georg E. Stahl (1660-1734) defendeu que o Phlogiston é o elemento geral da natureza, presente em minerais, vegetais e animais. Phlogiston é o princípio do fogo. Esse elemento apresenta um ciclo na natureza: presente em toda matéria, seja orgânica ou inorgânica, ele circula por meio de sua constante regeneração a partir da decomposição de animais e plantas se acumulando nos minerais e reciclando-se para a matéria orgânica uma vez mais. Trata-se de um ciclo ecológico, semelhante ao ciclo do dióxido de carbono, hoje documentado. Todos os processos fisiológicos dependem desse elemento geral (Christensen, 1994).

Em Quesnay (1747) o fogo ainda pode ser reduzido a um elemento mais geral. Nesse ponto Quesnay articula a metafísica, uma presença quase que incontornável no pensamento natural do século XVIII, com sua formação médica. Quesnay se apoia em uma ideia da Antiguidade, uma vez mais a influência das formações de natureza canônica nas ciências médicas e naturais do século XVIII. Porém, ao mesmo tempo, Quesnay está atualizado com os avanços de seus contemporâneos, especialmente na química. Assim, por meio da influência de Stahl e de seus discípulos, Quesnay formula que o movimento na matéria, a questão mais relevante em disputa na filosofia natural do século XVIII, é devido a um elemento genérico e abstrato. Essa filiação ao vitalismo surge em Quesnay com a proposição de que este Princípio Vital é o Éter.

Este Éter é geral, indivisível, portanto o elemento mais geral da natureza, e possui um caráter ativo, pois penetra todos os poros de cada criatura viva concedendo-lhes a energia para os processos vitais e fisiológicos. Ao criar o movimento na matéria, o Éter é também a fonte de calor nos corpos. Os processos fisiológicos mais importantes dentro do reino natural devem ser explicados pelo trabalho deste elemento sutil e geral. Reprodução, nutrição e movimento todos são oriundos das funções do Éter no corpo. Em linha com a herança da Antiguidade, Quesnay (1747) entende que o Éter nada mais é do que a alma vegetativa. Ele fornece sensibilidade, movimento e sabedoria natural aos tecidos, órgãos e fluidos. O Princípio Vital explica a regeneração do Pólipo de Trembley.

Mas o que é esse agente primitivo? Não é difícil separá-lo dos demais princípios da carne, nem de todos os outros fluidos; uma vez que apenas o Éter, que tem por si só sua atividade e fluidez e a partir do qual todos os outros fluidos derivam todas as suas qualidades ativas (Quesnay, 1747, p. 110) ${ }^{10}$.

\footnotetext{
${ }^{10}$ Mais quell est cet Agent primitive? Il n'est pas difficile de le démêler d'avec les autres príncipes des Corps, ni d'avec tous les autres fluides; puisqu'il n'y a que l'Ether qui ait par lui-même son activité e sa fluidité et que tous les autres fluides empruntent de lui toutes leurs qualités actives. (QUESNAY, 1747, p. 110).
} 
Mais um ponto relevante refere-se ao fato de que Quesnay (1747) compreende que a nutrição, ou seja, a alimentação dos tecidos por meio do seu contato com os humores não ocorre nos vasos sanguíneos. $\mathrm{Na}$ verdade, o movimento da natureza se dá na conjunção entre músculos e nervos, no que hoje se chama de junção mioneural ou neuromuscular. Dessa forma, o sangue não pode se apresentar como analogia para a circulação do produto líquido no Tableau. Essa proposição, tão recorrente na História do Pensamento Econômico, vai de encontro à formação fisiológica de Quesnay. Assim, o Princípio Vital age nos pequenos vasos nervosos e não na circulação sanguínea:

Digamos mais, pois o fato é certo; o Princípio Vital, na verdade tem uma grande atividade, e não a recebe senão a partir desse Éter. É, portanto, não nas outras partes que podem se articular com o Éter, mas sim no fluido de nervos, que reside o Princípio Vital, cuja atividade é a causa primária de todos os movimentos do corpo: O Princípio Vital nada mais é do que o Éter, retido nos nervos [...] (Quesnay, 1747, pp. 111-112) ${ }^{11}$.

Isso é importante porque fornece o reconhecimento de que Quesnay tinha pleno conhecimento das descobertas de Harvey (1993 [1628]). No capítulo final Harvey conclui:

Como todas as coisas, ambos, os argumentos e a demonstração visual, mostraram que o sangue passa através dos pulmões e do coração pela ação dos ventrículos e do átrio e é distribuído para todas as partes do corpo, onde passa através das veias e poros da carne, e em seguida, flui através das veias que rodeiam todos os lados em direção ao centro, a partir dos menores vasos para as veias maiores, e é por eles finalmente descarregado na veia cava e no átrio direito do coração, em tais quantidades e em tal fluxo, de maneira que não podem ser fornecidos pela dieta e em fluxo muito maior do que o necessário para o mero propósito de nutrição. É absolutamente necessário concluir que o sangue está em constante estado de movimento graças ao pulso do coração e que a circulação é a única função do movimento de contração do coração (Harvey, 1993 [1628], p. 145; itálicos pelo autor $)^{12}$.

\footnotetext{
${ }^{11}$ Disons plus, le fait est certain; puisque le principle Vital a réellement une très grande activité, et qu'il ne pas la recevoir que de lÉther. Ce n'est donc pas dans les autres parties que peuvent composer avec l'Ether, que le fluide des nervs, que reside le príncipe Vital, dont l'activité est la première cause de tous les mouvements du Corps: Le príncipe Vital n'est donc que l'Ether même, retenu dans les nervs avec le fluide qui peut être refermé avec lui dans ces mêmes nervs (QUESNAY, 1747, p. 111-112).

${ }^{12}$ Like all things, both arguments and visual demonstration showed that the blood passes through the lungs and heart by the action of the ventricles and atrium and is distributed to all parts of the body, where it passes through the veins and pores of the flesh, and then flows through the veins surrounding all sides towards the center, from the smaller to the larger veins, and is by them finally discharged into the vena cava and right atrium of the heart, in such quantity and at such ebb and flow through the
} 
Quesnay (1747) fornece indicações muito claras para se identificar sua posição relativa nos debates fisiológicos e químicos em meados do século XVIII. Por meio da análise das mudanças gerais na filosofia natural, que passou da abordagem mecanicista para uma visão mais ampla e eclética que combina neo mecanicistas, vitalistas e outras escolas de pensamento, foi possível precisar as abordagens médica e fisiológica de Quesnay em seu próprio contexto: ele é um praticante de sangrias e, como tal, ainda está sob a influência da antiga sabedoria da Antiguidade (a teoria dos humores).

Mas, ao mesmo tempo, Quesnay é sensível aos avanços da química que foram desenvolvidos para responder às limitações da teoria mecanicista. Nesse sentido, Quesnay foi capaz de identificar em processos químicos a própria natureza do movimento nos tecidos, órgãos e no corpo. Em Quesnay (1747) o Éter é a substância química primitiva que fornece movimento aos músculos por meio das minúsculas terminações nervosas. Além disso, à semelhança de Stahl, Quesnay (1747) entende o Éter como um elemento ecológico que garante a manutenção e reprodução contínua da ordem natural. De que forma esta construção intelectual seria um legado para o Tablean Économique?

\section{AS BASES FISIOLÓGICAS DA ECONOMIA POLÍTICA DO TABLEAU ÉCONOMIQUE}

Se houver de fato alguma herança fisiológica que se inscreve no Tableau, esta deve ser entendida a partir das relações entre o funcionamento do Princípio Vital e os dispêndios de capital por parte do fermier (Quesnay, 1984 [1756]). Isso significa que o entendimento do Tableau como uma analogia entre a circulação sanguínea e a circulação nominal e real do produto líquido no corpo político contradiz a formação do pensamento médico de Quesnay e representa uma interpretação contemporânea equivocada das recorrentes analogias entre corpo político e natureza, de fato em voga nos século XVIII.

A contribuição mais duradoura para a ideia de que o Tableau teve uma origem na formação médica de Quesnay encontra-se em Foley (1973). O argumento de Foley (1973) ligando a fisiologia à economia política do Tableau começa com a suposição de que Quesnay negligencia a circulação pulmonar do sangue. Foley (1973, p. 130) afirma que "Quesnay acreditava que a circulação pulmonar era tão lenta que poderia ser negligenciada na economia metabólica do corpo". Curiosamente, Quesnay (1750, pp. 88-91), como citado por Foley (1973, p. 130), não trata da circulação pulmonar, mas sim do temperamento melancólico e de como a

arteries and veins in such a way that it cannot be supplied by the diet, and much larger than necessary for the mere purpose of nutrition. It is absolutely necessary to conclude that the blood is in constant state of motion and that is the act or function which the heart performs by means of pulse and that is the only function of the movement of contraction of the heart (Harvey 1993 [1628] p. 145). 
espoliação pode tratar febres relacionado a este desequilíbrio de temperamento. Tratamento que está em absoluta conformidade com o pensamento médico na França do século XVIII como anteriormente descrito.

Além disso, como poderia Quesnay (1750) sustentar que o sangue assume diferentes velocidades no corpo uma vez que ele já havia provado, em sua disputa com o então eminente médico Jean Baptiste Silva (1727), que a hidrodinâmica impõe a equalização da velocidade dos fluxos? ${ }^{13}$ Além disso, Quesnay estava ciente das descobertas do aparelho circulatório feitas por Borelli (1680 e 1681) e Malpighi (1661), o que significa que os fluxos de sangue têm a tendência a fluir por todo o corpo humano com a mesma velocidade. Isso compreende a circulação pulmonar:

É óbvio que, se a quantidade de sangue que sai do sangramento é reparada por uma quantidade similar de sangue que corre na direção oposta, tudo é restaurado para o mesmo estado de antes; as resistências vão se reunir em torno do mesmo equilíbrio (Quesnay, 1750, p. 190) ${ }^{14}$.

Foley (1973) condiciona sua "Origem do Tableau" à alegada ausência da circulação pulmonar no pensamento fisiológico de Quesnay. Esta reivindicação é importante no argumento de Foley (1973, p. 130) uma vez que o sangue, assim como as rendas dos nobres no Tableau, deve ser dividido em dois fluxos quando sai do coração. Esta divisão dupla "traz para o foco vários pontos-chave sobre a hipótese de que a teoria econômica de Quesnay é influenciada por sua formação médica".

No entanto, Quesnay (1747, pp. 422-423) não negligencia circulação pulmonar em sua explicação da Economia Animal. Na verdade, a circulação pulmonar detém enorme relevância no sistema natural de Quesnay. É por meio da respiração que o Éter, o Princípio Vital, entra no corpo. Além disso, o ar nos pulmões fornece mais uma fonte de energia para a circulação sanguínea, para além do coração e da contração das artérias (a medicina do século XVIII acreditava que o tecido elástico das artérias estava associado a sua alegada função de bombear o sangue).

Quando o sangue é expelido pelo ventrículo direito do coração, ele é empurrado para dentro da artéria pulmonar que o distribui no pulmão, e é levado de volta pela veia pulmonar, que o reporta ao ventrículo esquerdo do coração, onde é expelido para imediatamente repetir o mesmo movimento.

\footnotetext{
${ }^{13}$ A questão em disputa eram os efeitos curativos da sangria sobre feridas e febres. O argumento da Silva (1727) estava baseado na suposição de que os fluxos de sangue assumem diferentes velocidades durante a sangria o que resultaria no equilíbrio nos humores e restauraria a saúde. Quesnay (1750) usa a hidrodinâmica em sua experiência com tubos de estanho para que a velocidade do sangue no sistema circulatório é sempre a mesma (Silva, 1727; Foley, 1973; Christensen, 1994).

${ }^{14}$ Il est evident en effet que si la quantité de sang qui sort par la saignée est réparée par une pareille quantité de sang qui survient, tout est rétabli dans le même état qu'auparavant; les resistances se retrouveront partout dans le même équilibre. (Quesnay, 1750 p. 190).
} 
A pressão contínua do ar que respiramos, muito contribui para o movimento do sangue que flui através do pulmão. É ainda absolutamente necessária para encaminhar o sangue nos vasos deste órgão [...]

[...] E o nosso corpo é uma máquina, na qual os movimentos interiores dependem de uma causa externa, e assemelha-se às máquinas movidas à água ou vento (Quesnay, 1747, pp. 422-423) ${ }^{15}$.

Um elemento importante no texto citado é a analogia do corpo humano com máquinas hidráulicas ou eólicas. Traços das heranças mecanicistas no pensamento fisiológico de Quesnay. Dessa forma, se a economia política está relacionada ao corpo político, o uso de máquinas como uma analogia para explicar a "Oeconomie" política se encaixa perfeitamente no discurso do século XVIII. O Tableau Économique é a descrição de uma máquina, um instrumento heurístico que visa explicar os efeitos da política fiscal nos fluxos de receitas e despesas.

A dupla divisão do sangue, portanto, pode ser vista como um legado do raciocínio fisiológico de Quesnay para sua teoria econômica somente se a circulação pulmonar for negligenciada. Nesse ponto Foley (1973, pp. 130-131) argumenta que Quesnay não estaria consciente da relevância fisiológica da circulação pulmonar, porque "Em algum ponto no tempo as contribuições de Harvey haviam sido corrompidas". Aqui duas reivindicações importantes devem ser levantadas: primeiro, uma vez que Harvey desempenha um papel fundamental na história da medicina e na revolução científica, é necessário sustentar por fontes documentais exatamente quando as descobertas de Harvey foram corrompidas. Em segundo lugar, como demonstrado acima, Quesnay $(1747$, p. 148) não está alheio à importância da circulação pulmonar: "A descoberta da circulação jogou grandes luzes na física da economia animal".

Esta dupla divisão do fluxo de sangue do ventrículo esquerdo deu origem à famosa analogia que poderia traduzir fisiologia em economia:

Assim, uma grande semelhança entre a circulação do Tabelau e a circulação descrita na obra médica de Quesnay publicada um quarto de século antes reside no fato de que ambos começam com uma divisão inicial do meio circulante em dois fluxos separados e iguais (Foley, 1973, p. 134).

Neste ponto, Foley (1973) argumenta que esta é exatamente a razão pela qual

\footnotetext{
${ }^{15}$ Lorsque le sang est arrive au ventricule droit du Coeur, il est poussé dans l'artere pulmonaire qui le distribue dans le poumon, et il est repris par la veine pulmonaire qui le rapporte au ventricule gauche du Coeur, d'où il est chassé aussitôt pour recommencer la même circulation. [...] La pression momentanée et successive de l'air, que nous respirons, contribui beaucoup au mouvement du sang qui circule dans le poumon. Elle est même absolument nécessaire pour faire cheminer le sang dans les vaisseaux de ce viscere $[\ldots][\ldots]$ ainsi notre corps est une machine, don't les mouvemens interieurs dépendent d'une cause extérieure, et qui ressemble en cela aux machines que l'eau ou le vent mettent an movement (Quesnay, 1747, p. 422-423).
} 
Quesnay "decidiu dividir sua sociedade hipotética em duas e apenas duas classes sociais" (p. 134). Mas essa é uma proposta enganosa. Quesnay é bastante explícito na apresentação da sua classificação econômica da sociedade: "A nação é reduzida à três classes de cidadãos: a classe produtiva, a classe dos proprietários e a classe estéril” (Quesnay, 1886, p. 305).

Reduzir a estratificação social proposta por Quesnay em apenas duas classes é funcional no argumento de Foley (1973), pois essa distorção dá origem à analogia que liga as classes sociais ao sistema circulatório. Primeiro Foley (1973) argumenta que em meados do século XVIII a medicina acreditava que as artérias possuíam a propriedade de contração, o que daria pressão e movimento aos fluxos sanguíneos. A classe produtiva é, dessa forma, identificada com as artérias já que apenas essa classe agrega valor, o que significa que essa classe, como as artérias, desempenha um papel ativo no sistema. As veias, que por sua vez servem como canais passivos pelos quais o sangue flui, têm a sua tradução na estrutura social na classe estéril (Foley, 1974, pp. 134-136).

Foley (1973) tenta traduzir a característica mais importante de pensamento fisiocrático, qual seja, a exclusividade de agricultura como a fonte do produto líquido, na estrutura básica do sistema circulatório. Mas neste ponto a anatomia fornece provas contra a analogia de Foley: é a aorta, uma artéria que leva o sangue do ventrículo esquerdo para ambas as classes, estéril e produtiva. A anatomia da aorta era bem conhecida pelos praticantes da medicina do século XVIII. Para sustentar que a classe estéril pode ser traduzida como veias do sistema é necessário admitir que esta classe pode transformar o sangue arterial em sangue venoso. Mas, novamente, desde Borelli (1680 e 1681) e Malpighi (1661) no final do século XVII, os fisiologistas sabem que a troca gasosa ocorre nos pulmões.

Mais um ponto deve ser desenvolvido para se afastar a origem do Tableau na analogia com o sistema circulatório: mesmo se Quesnay (1750, p. 166) é explícito ao reconhecer que "O sangue é dividido fora do ventrículo esquerdo do coração em duas correntes [...]", essa proposição deve ser vista como uma pura descrição anatômica e não como um traço genético a ser encontrado, anos depois, em sua teoria econômica. Simplesmente porque se as rendas dos nobres não forem divididas entre bens manufaturados e bens agrícolas desde o primeiro dispêndio do ano fiscal, outras subdivisões das despesas dentro e entre as classes produtivas e estéreis não garantiria o equilíbrio final em termos da composição da demanda agregada e do valor das trocas ${ }^{16}$.

Por fim, não é o sangue que deve ser tomado como a medida e o tradutor da

\footnotetext{
${ }^{16}$ Já em 1767, institui-se um debate sobre os efeitos da composição setorial da demanda agregada sobre o nível do produto líquido tal qual no Tableau. Forbonnais (1767) sustentou que uma diminuição no produto líquido ocorreria apenas se a classe estéril não gastasse toda a sua renda em bens agrícolas. Caso contrário, toda a renda iria voltar para a classe produtiva e o padrão da despesa da classe proprietária não implicaria flutuações no volume do produto líquido. Baudeau, editor-chefe das Efemérides $d u$ Citoyen forneceu uma resposta às críticas de Forbonnais sem, contudo, abordar os pontos metodológicos e teóricos levantados por Forbonnais (Van den Berg, 2002).
} 
criação de riqueza na sociedade. A fim de sustentar a origem fisiológica do Tableau, o produto líquido não pode ser identificado com o sangue, mas sim com o funcionamento ecológico e fisiológico do Princípio Vital que dá origem ao movimento do sistema. Neste ponto, a leitura parcial dos escritos médicos de Quesnay pode trazer falsas conclusões e paralelos entre medicina e economia política. A dinâmica da economia política não está no sangue, mas sim nos nervos onde opera o Princípio Vital: "Foi reconhecido por todos os termos que esse primeiro princípio encontra-se dentro dos nervos e a experiência não permite duvidar disso" (Quesnay, 1747, p. 104). Esta abordagem converge para o ecletismo do pensamento natural de Quesnay.

Os argumentos acima visaram proporcionar incerteza sobre a origem fisiológica do Tableau associada à analogia com o sistema circulatório. Todas as reivindicações de que o Tableau pode compartilhar qualquer herança genética com a descrição da circulação sanguínea foram desconstruídas. O Tableau emerge como um instrumento heurístico, um modelo no sentido contemporâneo, que busca retratar a circulação nominal e real na economia. Qualquer herança fisiológica ou oriunda da filosofia natural para a economia política deve ser buscada nas influências que a química contemporânea deu à Quesnay. Como mencionado acima, o Éter é a fonte de movimento, calor e dos processos naturais, dentre os quais a geração do produto líquido. Nesse sentido, a hipótese da exclusividade da agricultura na geração do produto líquido pode ser explicada em termos químicos e, portanto, a partir da função ecológica desempenhada pelo Princípio Vital (Éter).

Portanto, já em Quesnay (1888 [1757]) pode-se identificar traços da influência de seu pensamento médico sobre sua nascente economia política:

[...] Mas o princípio de todos estes benefícios está na agricultura, que fornece a primeira necessidade material, que fornece as reservas para o Rei e para os proprietários, os dízimos ao clero e os lucros para os agricultores. Estas são riquezas sempre renovadas que suportam todos os outros estados do reino, que dão o esteio para todas as outras profissões, que estão florescendo no comércio que favorecem a população, que animam a indústria e que mantêm a prosperidade da nação (Quesnay, 1886 [1757], pp. 215-216) ${ }^{17}$.

$\mathrm{Na}$ última e ampliada edição de seu tratado sobre fisiologia, Essai Physique Sur L'Oeconomie Aniimale, de 1747, Quesnay fornece uma representação do papel "macroeconômico" do Princípio Vital, ou seja, o Éter como fonte de movimento na economia animal:

\footnotetext{
${ }^{17}$ [...] mais le principle de tous ces avantages est dans l'agriculture, qui fournit les matières de premier besoin, qui donne des reserves au roi et aux propriétaires, des dîmes au clergé, des profits aux cultivateurs. Ce sont ces premiéres richesses, toujours renouvelées, qui soutiennent tous les autres états du royaume, qui donnent de l'activité à toutes les autres professions, qui font fleurir le commerce, qui favorisent la population, qui animent l'industrie, qui entretiennent la prosperité de la nation (Quesnay, 1888 [1757], p. 215-216).
} 
Isto requer que o Espírito Vital retenha em si mesmo uma atividade que, a fim de dar à luz todos esses movimentos, não precisa mais do que de causas simples: músculos que são os órgãos por meio do qual as partes são colocadas em movimento, derivam sua força de uma força dirigida a eles pelo fluxo de sangue contínuo em suas fibras, o que os coloca na contração tão cedo quanto o líquido é atrasado ou interceptado nestas fibras; mas a intercepção ou retardamento da circulação do sangue nos músculos, depende de uma primeira força que produz as fibras desses músculos [...] Ora, esta primeira força reside nos nervos [...] (Quesnay, 1747, pp. 109-110) ${ }^{18}$.

Esta "première force" é o "princípio ao qual devemos atribuir esta enorme atividade do Espírito Animal, o que nos dá todas as nossas sensações e que faz mover todos os nossos órgãos" (Quesnay, 1747, pp. 112-113). Não sangue, mas Éter é a substância nutritiva de ambas, a economia social e animal. Portanto, o Tableau não é uma analogia ao sistema circulatório, nem uma recreação racional como apontado por Charles (2003). O Tableau é um instrumento heurístico que retrata a função sútil e invisível do Éter na economia animal e social.

\section{CONCLUSÕES}

François Quesnay desenvolveu uma abordagem eclética no seu pensamento fisiológico. Como cirurgião, ele era um adepto das práticas de sangria, o que o filiava à canônica teoria dos humores de Hipócrates e Galeno. Mesmo antes de sua graduação em medicina (1744), Quesnay estava trabalhando em filosofia natural e fisiologia (Quesnay, 1736). Em um contexto em que a escola mecanicista era posta em dúvida pelas descobertas da química e da biologia, Quesnay colocava-se em sintonia com as evoluções mais relevantes da química contemporânea. Sua adesão à teoria dos humores e sua afinidade com os avanços da química o levaram a adotar a abordagem vitalista. Essa abordagem, no entanto, não o eximiu de manter traços de uma visão um tanto mecanicista sobre o corpo humano. Hidrodinâmica, teoria dos humores e princípio vital foram se articularam no pensamento fisiológico de Quesnay, pouco antes de suas primeiras incursões na economia política.

A análise do contexto intelectual no qual se deram os debates do século XVIII sobre filosofia natural forneceu as ferramentas históricas e analíticas para a recons-

\footnotetext{
${ }^{18}$ Il faut donc que l'Espirit Vital ait par lui-même une activité qui n'ait besoin, pour faire naitre tous ces mouvements que des causes simplement déterminantes: les Muscles qui sont les organs par lesquels les parties sont mises en mouvement, on à la verité une force que leur comunique le Sang qui coule continuellment dans leurs fibres, et qui les met en contraction aussi-tôt que le cours de ce liquid est ou retardé, ou intercepté dans ces fibres; mais cette interception ou ce retardement de la circulation du Sang dans les Muscles, depend lui-même d'une premiere force qui produit dans les fibres de ces Muscles [...]. Or cette première force reside dans les Nerfs [...] (Quesnay, 1747, p. 109-110)
} 
trução da possível influência da fisiologia sobre a economia política presente no Tableau. Ao invés da circulação sanguínea, o Tableau recebe influência da fisiologia em um sentido muito mais amplo e condizente com a formação média de Quesnay: o Princípio Vital, ou seja, o Éter que torna possível a reprodução contínua do corpo político ao longo do tempo. É a característica ecológica e cíclica da química do Princípio Vital que fornece os rendimentos do capital alocado na agricultura. Portanto, o Tableau não é uma analogia para a circulação sanguínea. É uma aplicação do pensamento fisiológico de Quesnay para a economia política.

Para sustentar esta afirmação, além de identificar a posição relativa de Quesnay nos debates sobre o pensamento médico no século XVIII, o artigo construiu uma crítica à abordagem, de alguma forma tradicional, segundo a qual o Tableau deveria ser entendido como uma analogia ao sistema circulatório (Foley, 1973). Esta crítica foi construída com base nos próprios escritos fisiológicos de Quesnay.

O artigo conclui que é possível reunir o Tableau com o pensamento fisiológico anterior desenvolvido por Quesnay (1736 e 1747). Mas essa relação é muito mais sutil do que a simples analogia com a circulação sanguínea. Na verdade, esta possível linha genética da fisiologia à economia política em Quesnay está disseminada por toda a natureza na forma metafísica de um Éter.

\section{REFERÊNCIAS BIBLIOGRÁFICAS}

BARNA, T. (1975) "Tableau in modern guise". The Economic Journal, 85, 339 (Sep): 485-496.

BAUER, Stephen (1890) "Studies on the origin of the French economics." The Quarterly Journal of Economics. 5, 1(Oct.): 100-107.

BERNAT, Pasqual (2013) "El Pólipo de Trembley: el animal-planta que transformó la biologia del siglo XVIII". Métode, 78: 33-37.

BILGINSOY, C. (1994) “Quesnay's Tableau Economique: analytics and policy implications”. Oxford Economic Papers, New Series, 46, 3 (Jul): 519-533.

BORELLI, J. A. (2011 [1680 and 1681]). On the movement of animals. Berlin, etc.: Springer-Verlag. [De motu animalium. Pars Prima. Roma: Angeli Bernabo, 1680 and De motu animalium. Pars altera. Roma: Angeli Bernabo, 1681].

BROMAN, Thomas (1989) "University reform in the medical thought at the end of the eighteenth century". Osiris, 2nd Series, Vol. 5, Science in Germany: The Intersection of Institutional and Intellectual Issues: 36-53.

CHARLES, Loïc (2003) “The visual history of the Tableau Économique". The European Journal of the History of Economic Thought, 10,4.

CHRISTENSEN, Paul P. (1994) "Fire, motion, and productivity: the proto-energetics of nature and economy in François Quesnay.” In Phillip Mirowsky ed. Natural Images in Economic Thought. Cambridge: Cambridge University Press.

DESCARTES, René (1677) L'Homme de René Descartes et la Formation du Foetus. Paris: Theodore Girard. http://gallica.bnf.fr/ark:/12148/bpt6k942459.

ELTIS, W. A. (1975) "François Quesnay: a reinterpretation 1. The Tableau Economique". Oxford Economic Papers, 27, 2 (Jul): 167-200.

FORBONNAIS, François Véron de (1767) Principes et observations oeconomiques. Amsterdam: Marc Michel Rey. http://books.google.co.uk/books?id=RTJXAAAAcAAJ\&printsec=frontcover\&hl=pt -BR\&source=gbs_ge_summary_r\&cad=0\#v=onepage\&q\&f=false 
FRIEDMAN, Mayer and FRIEDLAND, Gerald W. (2000) Medicine's 10 greatest discoveries. Yale: Yale University Press.

FOLEY, V. (1973) “An origin of the Tableau Économique”. History of Political Economy. 5, 1: 121-50.

GHERKE, Christian and KURZ, Heins D. (1995) "Karl Marx on physiocracy". The European Journal of the History of Economic Thought. 2, 1: 53-90.

GRASLIN, Jean-Joseph-Louis. (1911 [1767]) Essai Analytique sur la Richesse et sur limpôt. Paris: Librairie Laul Geuthner. http://gallica.bnf.fr/ark:/12148/bpt6k800687.r=.langPT

GROENEWEGEN, Peter (2001) "From prominent physician to major economist. Some reflectios on Quesnay's switch to economics in the 1750's." In P. Groenewegen, ed. Physicians and Political Economy. Six studies of the work of doctor-economists. London and New York: Routledge.

HAMILTON, Bernice (1951) "The medical profession in the eighteenth-century". The Economic History Review, 4 (2): 141-169.

HARVEY, William (1993 [1628]) On the motion of the heart and blood in animals. New York: Prometheus Books. [Exercitation anatomica de motu cordis et sanguinis in animalibus. Frankfurt am Main.]

KURLZ, Rolf (1984) Quesnay. Col. Grandes Cientistas Sociais. São Paulo: Ática.

MAITAL, S. (1972) “The Tableau Economique as a simple Leontief model: an amendment”. The Quartely Journal of Economics, 86, 3 (Aug): 504-507

MALPIGHI, Maecello (1958 [1661]) De pulmonibus. Roma: Societá Italiana di Istochimica.

MARCUZZO, Maria Cristina. (2008) “Is history of economic thought a “serious” subject?” Erasmus Journal for Philosophy and Economics. 1, 1 (Autumn): 107-123.

MARX, Karl (1966) El Capital. Ciudad de México, DF: Fondo de Cultura Económica.

MARX, Karl (1863) Theories of Surplus-Value. E-book. https://www.marxists.org/archive/marx/ works/download/prc/

MEEK, R. L. (1960) “The interpretation of the Tableau Economique”. Economica, 27, 108: 322-347.

MEEK, R. L. (2003 [1962]). The Economics of Physiocracy. London and New York: Routledge.

MITCHELL, Harvey (1979) "Rationality and control in French Eighteenth-Century medical views of the peasantry." Comparative Studies in Society and History. 21, 1 (Jan.): 82-112.

MOLIÉRE, J. B. P. (1815) Oeuvres de J. B. P. Molière. Tome Septième. Paris: Chez T Desoer.

ORAIN, Arnaud (2013) "Soutenir la guerre et reformer la fiscalité. Silhouette et Forbonnais au contrôle general des finances". French Historical Studies, 36, 3 (summer): 417-447.

QUESNAY, François (1736) Essai phisique sur l'economie animale. Paris: Guillaume Cavelier. http:// gallica.bnf.fr/ark:/12148/bpt6k829070.r=Quesnay\%2C+Fran\%C3\%A7ois.langPT.

QUESNAY, François (1747) Essai physique sur l'oeconomie animale. Seconde Edition. Paris, Guillaume Cavelier. http://gallica.bnf.fr/ark:/12148/bpt6k829070.r=Quesnay\%2C+Fran\%C3\%A7ois. langPT.

QUESNAY, François (1750) Traité des effets et de l'usage de la saignée. Nouvelle edition de deux traités de l'auteur sur la saignée, réunis, mis dans um nouvel ordre et três augmentés. Paris: D’houry. http://gallica.bnf.fr/ark:/12148/bpt6k2819495.r=Quesnay\%2C+Fran\%C3\%A7ois.langPT.

QUESNAY, François (1984 [1756]). “Fermiers”. In: Rolf Kurz (org.) Quesnay. Coleção Grandes Cientistas Sociais. São Paulo: Ática.

QUESNAY, François (1984 [1756]) “Evidência”. In: Rolf Kurz (org.) Quesnay. Coleção Grandes Cientistas Sociais. São Paulo: Ática.

QUESNAY, François (1888 [1757]) “Grains”. In: A. Oncken ed. Oeuvres économiques et philosophiques de F. Quesnay. Paris: Jules Peelman. http://gallica.bnf.fr/ark:/12148/bpt6k72832q. $\mathrm{r}=$ Oncken $\% 2 \mathrm{C}+$ August.langPT.

QUESNAY, François (1984 [1758]). Carta a Mirabeau in: KURLZ, Rolf. 1984. Quesnay. Col. Grandes Cientistas Sociais. São Paulo: Ática.

STEINER, Philippe. (2003) "Physiocracy and French pre-classical political economy". In: Warren J. Samuel; Jeff E. Biddle and, John B. Davis ed. A Companion to the History of Economic Thought. Malden, MA: Blackwell Publishing.

SCHUMPETER, J. A. (1954) History of Economic Analysis. London: Allen and Unwin. 
SERRANO, F. e MAZAT, N. (2013) "Quesnay and the analysis of surplus in an agrarian capitalist ecomomy”. MPRA Paper. 47781, (jun). http://mpra.ub.uni-muenchen.de/47781/

SILVA, Jean Baptieste (1727) Traité de l'usage des diferentes sortes de saignées, principalmente de celle $d u$ pied. Paris: D’Aannison, Directeur de l'Imprimerie Royale. http://babel.hathitrust.org/cgi/pt?i $\mathrm{d}=\mathrm{ucm} .5327730337$; view $=1$ up;seq=7

SMITH, Adam (1983 [1776]) Uma investigação sobre a causa e a natureza da riqueza das nações. São Paulo: Abril Cultural. Vol. 2.

SUTTER, J. (1958) “Quesnay et la medicine”. Quesnay, François. Quesnay et la Physiocratie. 2 V. Paris: Institute National de l'économie et de la demographie.

THÉRÉ, Christine (1998) “Economic publishing and authors, 1566-1779.” In Gilbert Faccarello, ed. Studies in the history of French political economy. London and New York: Routledge.

VAN den BERG, Richard (2002) “Contemporary responses to the Tableau Économique”. In Stephan Boehm, Christian Gehrke, Heinz D. Kurz and Richard Sturn (eds.) Is there progress in economics? Knowledge, truth and the history of economic thought. Cheltenham: Edward Elgar.

VARDI, Liana (2012) The Physiocrats and the world of enlightenment. Cambridge and New York: Cambridge University Press.

VIAGGI, G. (1985) "A physiocratic model of relative prices and income distribution". The Economic Journal, 95, 380 (Dec.): 928-947.

WALRAS, Leon (1996 [1874]) Compêndio dos Elementos de Economia Política Pura. São Paulo: Nova Cultural. 